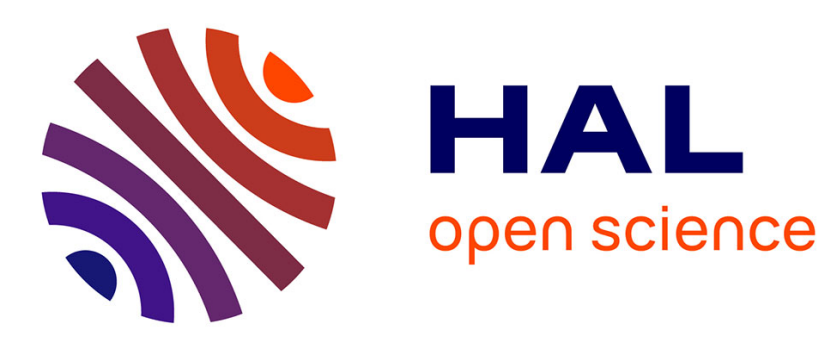

\title{
Dual Band Meander Line Antenna for Wireless LAN Communication
}

\author{
Ali Khaleghi
}

\section{To cite this version:}

Ali Khaleghi. Dual Band Meander Line Antenna for Wireless LAN Communication. IEEE Transactions on Antennas and Propagation, 2007, 55 (3), pp.1004-1009, Volume: 55, Issue: 3, Part 2,. 10.1109/TAP.2007.891873 . hal-00171676

\section{HAL Id: hal-00171676 https://hal.science/hal-00171676}

Submitted on 12 Sep 2007

HAL is a multi-disciplinary open access archive for the deposit and dissemination of scientific research documents, whether they are published or not. The documents may come from teaching and research institutions in France or abroad, or from public or private research centers.
L'archive ouverte pluridisciplinaire HAL, est destinée au dépôt et à la diffusion de documents scientifiques de niveau recherche, publiés ou non, émanant des établissements d'enseignement et de recherche français ou étrangers, des laboratoires publics ou privés. 


\section{Dual Band Meander Line Antenna for Wireless LAN Communication}

\author{
A. Khaleghi
}

\begin{abstract}
A printed meander line antenna is described with a shaped ground plane and a back coupled rectangular patch. The prototype is proposed for wireless local-area network (WLAN) applications in the 2.4-2.48 GHz and 5.15-5.35 GHz frequency range. Dual-band operation, resonance impedance matching, and wide impedance bandwidth are the characteristics of the antenna. The antenna impedance matching for the first-resonance is provided by applying a shaped ground plane. The second even-mode resonance is generated by adding a rectangular patch at the back of the meander antenna. The impedance bandwidth for a return-loss less than $-10 \mathrm{~dB}$ is $11 \%$ and $6 \%$ for the first- and the second-resonance, respectively. Furthermore, the second-resonance frequency can be tuned by the length of the rectangular patch and it meets the requirements for the IEEE 802.11a WLAN (5.15-5.35 GHz and 5.470-5.725 GHz or $5.725-5.825 \mathrm{GHz}$ ). In fact, the second-resonance frequency can be continuously adjusted between 5.2 and $7 \mathbf{G H z}$ with a little effect on the first-resonance.
\end{abstract}

Index Terms-Antenna, dual-band, efficiency, meander line, wideband, wireless local area network (WLAN).

\section{INTRODUCTION}

Radio-based LANs are becoming more and more flexible and even a less expensive option in dynamic environments, than today cable based systems. Most of wireless local area network (WLAN) systems are designed to operate in the $2.4-2.48 \mathrm{GHz}$ and $5 \mathrm{GHz}$ frequency bands. In the United States, the frequency range of 5.15-5.35 GHz and $5.725-5.825$, in Europe, the frequency range of 5.15-5.35 GHz and $5.470-5.725 \mathrm{GHz}$ provide data rate up to $54 \mathrm{Mbps}$. A compact communication system working in these frequency bands requires a low profile, dual-band/wideband antenna. Meander line technology allows small size antenna designing and wideband operation [1], [2].

The characteristics of printed meander line monopole on a dielectric slab sitting on a small ground plane have been investigated for personal wireless communication (PCS) [1], [3]. The antenna employs odd-mode resonance impedance and the input impedance for the firstand third-harmonic frequency is not appropriate to match the traditional $50 \Omega$ impedance of the communication device. Therefore, additional tuner traces or circuits are needed [1], [2]. Dual-sleeve tuning of the meander line monopole antennas is possible and provides good impedance matching [1] but the ratio of two sequential operating frequencies is always less than factor two that is required for our application for 2.4 and $5 \mathrm{GHz}$ bands.

In this paper, a printed double meander antenna with an adaptive feed line is presented. For the impedance matching in the $2.4 \mathrm{GHz}$ a shaped ground plane is applied. Using a back coupled parasitic rectangular patch, with a gap distance from the shaped ground, provides the second-resonance in the $5 \mathrm{GHz}$ band. The length of the rectangular patch is applied to tune the second-resonance within 5.2-7 GHz. Meanwhile, the first resonance is almost constant. The antenna design procedures, simulation for return-loss and current distribution are presented.

Manuscript received March 17, 2006; revised July 28, 2006.

The author is with the Institut d'Electronique et de Telecommunication de Rennes (IETR)-UMR CNRS 6164-INSA, 35043 Rennes Cedex, France (e-mail: ali.khaleghi@insa-rennes.fr).

Color versions of one or more of the figures in this paper are available online at http://ieeexplore.ieee.org.

Digital Object Identifier 10.1109/TAP.2007.891873
Measurement results include, return-loss, 3-D pattern, antenna gain and efficiency are demonstrated.

\section{ANTENNA DESIGN AND ANALYSIS}

A printed double meander line monopole antenna with uniform vertical and horizontal segmental ratio is designed to operate in the $2.4 \mathrm{GHz}$ frequency band [11]. Fig. 1 shows the geometrical configuration of the proposed antenna. The meander line width $W_{L}=0.6 \mathrm{~mm}$, equal vertical and horizontal segments $e_{1}=e_{2}=3.1 \mathrm{~mm}$ are considered. The antenna is printed on FR4 $\left(\varepsilon_{r}=4.2\right.$ and $\left.\tan \delta=0.01\right)$ substrate slab with width $W_{s}=9 \mathrm{~mm}$ and substrate thickness $t_{s}=1.6 \mathrm{~mm}$. The meander antenna is sited on top of a standard SMA type connector considered as the antenna ground plane and is fed through the coaxial core of the connector. The meander line antenna length, $L_{\mathrm{ax}}$, is selected about $\lambda / 4$ ( $\lambda$ is the wavelengths) and is optimized to bring a resonance frequency of $2.45 \mathrm{GHz}$. The Increase of the antenna length decreases the value of the first resonance frequency. For the present design the optimized length is $L_{\mathrm{ax}}=31.3 \mathrm{~mm} .10$ equally distributed sections for the vertical lines are selected. The prototype detail dimensions are tabulated in Table I.

The meander line antenna is modeled and optimized using three dimensional time-domain transmission line matrix (TD-TLM) method code. Time domain solution is quite useful when broad band frequency data is needed or when the exact location of response in the frequency domain are not known. In the simulation procedure the boundary condition is set as absorbing and the computation space is extended by $30 \%$ of the total volume of the structure. The dimensions of the grids around the structure depending on the region are different selected in order to precisely construct the antenna model after the structure discretizing. Using time-domain solution based on TLM code has the features of fast computation time and small allocated memory.

To provide appropriate resonance impedance, wideband impedance matching in the antenna input and mechanical stability a linearly tapered part is used between the coaxial feed and the meander antenna. The computed return-loss versus frequency is depicted in Fig. 2. As shown, three sequential resonances are generated for $2.3,4.8$, and $7 \mathrm{GHz}$ and the return-loss for the first-resonance frequency is only $-4.5 \mathrm{~dB}$.

To generate better impedance matching, a shaped ground plane is printed at the back of the meander antenna on the substrate slab. The dimensions of the ground patch are optimized using EM solution code to provide better impedance matching for the first-resonance. Good impedance matching is resulted using a shaped patch with the dimensions $\left(W_{1}, W_{2}, L_{1}\right)$ given in Table I (see Fig. 1). The simulated return-loss versus frequency is illustrated in Fig. 2. As shown, due to the shaped ground plane, the antenna is better matched to the $50 \Omega$ characteristic impedance of the coaxial line. The first-resonance frequency of the antenna is increased to $2.6 \mathrm{GHz}$, the second-resonance is eliminated and the third resonance is almost constant.

A laboratory prototype of the antenna (on FR4) is constructed and the return-loss is measured by connecting the antenna via coaxial cable to a network analyzer. The measurement of the small antenna needs some considerations. The ground base of the antenna is small and the current flow on the meander line antenna at the resonance frequency is strong; this causes to the current coupling on the feed cable and consequently the radiation of the cable. In order to suppress the current coupling on the feed cable, equally to reduce the distortion of the impedance and radiation patterns, a coaxial cable with ferrite beads is implemented [9]. The measured return-loss versus frequency is illustrated in Fig. 2. The agreement between the measured and computed curve is good. The antenna is well matched to $50 \Omega$ impedance and provides return-loss 

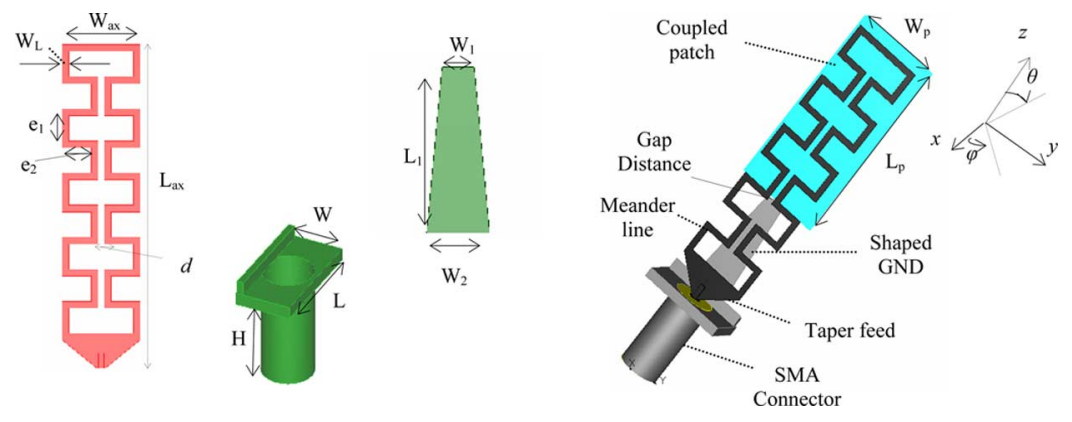

Fig. 1. Meander antenna prototype with the shaped ground plane and the back coupled rectangular patch.

TABLE I

Dimensions of the Meander Antenna With Shaped Ground Plane and Coupled Patch (See Fig. 1)

\begin{tabular}{|l|c|c|c|c|c|c|c|c|c|c|c|c|c|c|}
\hline Parameters & $\mathbf{L}_{\mathbf{a x}}$ & $\mathbf{W}_{\mathbf{a x}}$ & $\mathbf{e}_{\mathbf{1}}$ & $\mathbf{e}_{\mathbf{2}}$ & $\mathbf{W}_{\mathbf{L}}$ & $\boldsymbol{d}$ & $\mathbf{W}_{\mathbf{1}}$ & $\mathbf{W}_{\mathbf{2}}$ & $\mathbf{L}_{\mathbf{1}}$ & $\mathbf{H}$ & $\mathbf{W}$ & $\mathbf{L}$ & $\mathbf{L}_{\mathbf{p}}$ & $\mathbf{W}_{\mathbf{p}}$ \\
\hline Value(mm) & 31.3 & 7.5 & 3.1 & 3.1 & 0.6 & 2 & 4 & 2 & 11 & 9.5 & 6 & 9 & variable & 9 \\
\hline
\end{tabular}

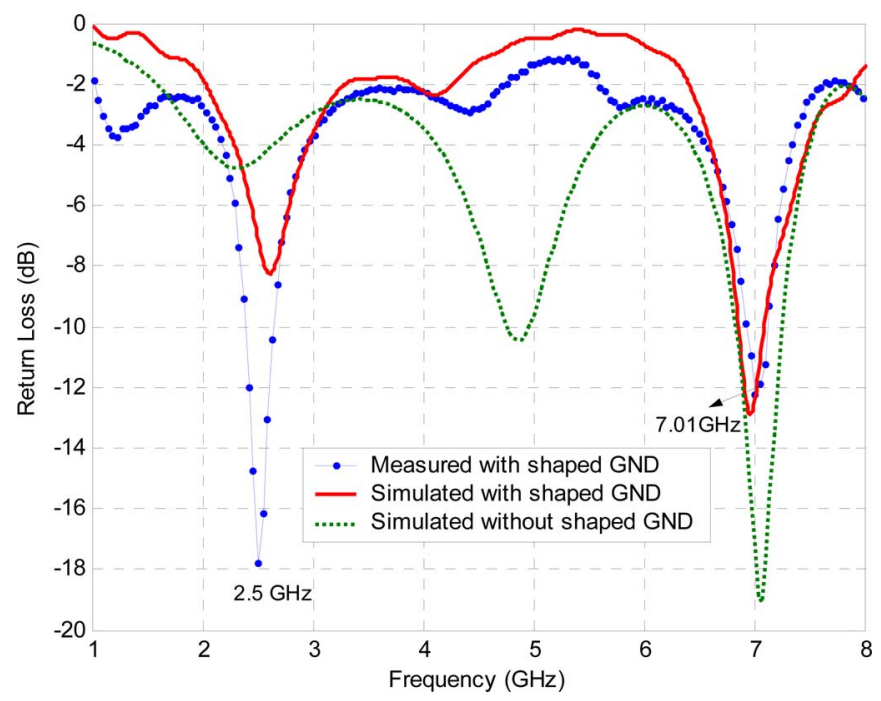

Fig. 2. Computed return-loss (decibels) of the meander line antenna with and without the shaped ground plane; the measured return-loss with the shaped ground plane effects is also illustrated.

$-18 \mathrm{~dB}$ in the $2.5 \mathrm{GHz}$ frequency. The measured impedance bandwidth for return-loss less than $-10 \mathrm{~dB}$ is $250 \mathrm{MHz}$. This exceeds the requirement of the IEEE $802.11 \mathrm{~b}$ LANs operates in the $2.4-2.48 \mathrm{GHz}$ frequency range.

The second-resonance frequency of the antenna can be tuned to IEEE 802.11a LANs in the $5 \mathrm{GHz}$ frequency band. For this reason, a rectangular patch with $W_{p}=9 \mathrm{~mm}$ and $L_{p}=20 \mathrm{~mm}$ is added at the back of the meander line antenna on the dielectric slab (see Fig. 1). The rectangular patch should be placed with a small air gap distance $\left(t_{g}=0.2 \mathrm{~mm}\right)$ to the shaped ground plane. Using the proposed back coupled patch technique, the second-resonance frequency is generated in the $5.25 \mathrm{GHz}$ and the first-resonance frequency stays almost constant. Fig. 3 shows the simulated and the measured return-loss of the meander line antenna with the coupled patch effects. As shown, the antenna has resonance at both 2.45 and $5.25 \mathrm{GHz}$ (dual operational bands) with almost $50 \Omega$ impedance. The measured impedance bandwidth of the antenna for the return-loss less than $-10 \mathrm{~dB}$ in the $2.45 \mathrm{GHz}$ is $270 \mathrm{MHz}(11 \%)$ and in the $5.25 \mathrm{GHz}$ is $315 \mathrm{MHz}(6 \%)$. This property makes the design appropriate for the IEEE $802.11 \mathrm{a}, \mathrm{b}$ LANs operates in the $2.42-2.48 \mathrm{GHz}$ and $5.15-5.35 \mathrm{GHz}$ frequency ranges. The resulted

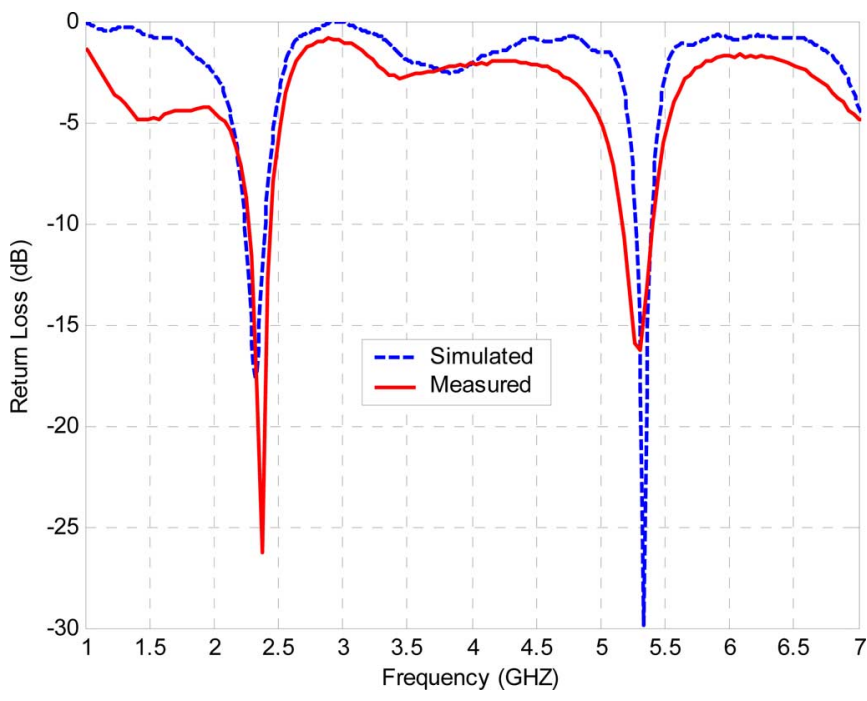

Fig. 3. Measured and simulated return-loss (decibels) versus frequency for the meander line antenna with the rectangular patch effects.

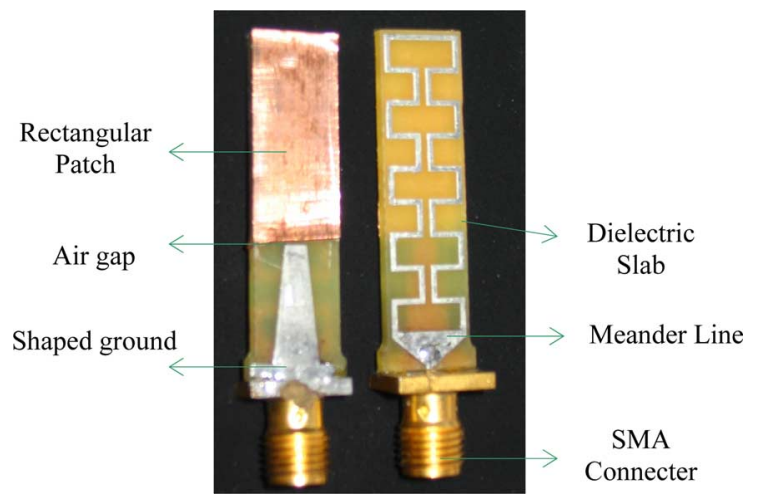

Fig. 4. Photograph of the meander line antenna with the coupled patch.

wideband operation is derived from the inherent nature of the meander antenna. Fig. 4 shows the photograph of the constructed antenna, different parts of the antenna structure are depicted on the photo.

In practical applications, the antenna may be vertically installed above a large horizontal ground plane or on the edge of a $90^{\circ}$ bended 


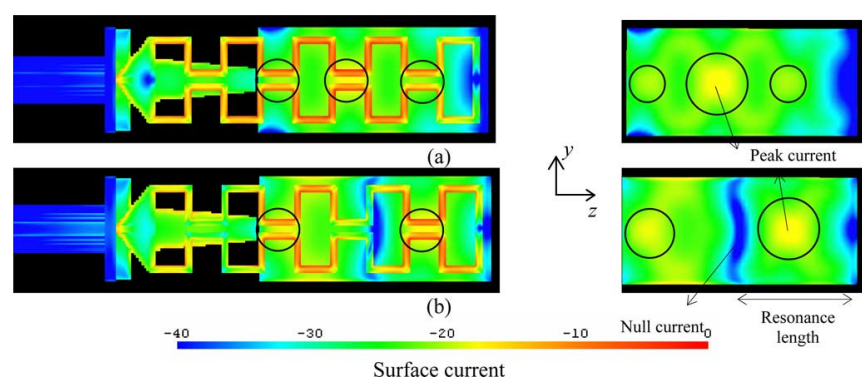

Fig. 5. Computed average current density on the meander line antenna structure and the rectangular patch (a) $2.45 \mathrm{GHz}$ and (b) $5.25 \mathrm{GHz}$; the circles show the peak current locations.

ground plane. If this is the case, the first-resonance impedance matching would be influenced. To keep the previous characteristics, the antenna should be elevated at least $5 \mathrm{~mm}$ above the ground surface when measured in relation to the SMA connector base. In this case, we could abandon the use of the coaxial cable with the ferrite beads for the antenna measurements.

Fig. 5 shows the average current density on the meander line antenna and the rectangular patch in the 2.45 and $5.25 \mathrm{GHz}$. The current distribution along the meander line antenna is in the $z$-axis direction; this results to high current density at the regions where two strip lines are closed. The strong current density couples the high current on the rectangular patch. In the $2.45 \mathrm{GHz}$ the rectangular patch length and the maximum current locations (see Fig. 5(a); shown with circles) are not convenient to bring the resonance on the rectangular patch. Therefore, the influence of the patch on the location of the first-resonance would be small.

In the $5.25 \mathrm{GHz}$ two peak currents are observed on the rectangular patch. The length of the patch and the location of the peak current are appropriate to support a half-wave resonance in the $5.25 \mathrm{GHz}$ [see Fig. 5(b)]. Consequently, the second resonance is supported by the rectangular patch. A sobering observation is to change the length of the rectangular patch for the tuning of the second-resonance frequency (see Section V).

\section{FARFIELD RADIATION PATTERN}

Antenna radiation pattern and gain were measured in Supelec anechoic chamber with spherical pattern measurement facility. To suppress the effects of the cable on the radiation pattern, a coaxial cable with ferrite beads is used. The introduced attenuation of the ferrite beads cause to a reduced antenna gain that is included in the presented results [9].

A wideband $(2-18 \mathrm{GHz})$ horn antenna was used as field probe and the antenna gain and radiation patterns were measured for $\theta$-polarized and $\varphi$-polarized field components. The 3 -D pattern of the antenna is measured for the operating frequencies in the 2.45 and $5.25 \mathrm{GHz}$. Fig. 6 shows the measured 3-D power pattern of the antenna. The antenna pattern is measured with $5^{\circ}$ resolution of the $\theta$ and $\varphi$ of the spherical coordinate system. The measurement of the pattern for $\theta$, spherical angles, is limited to $140^{\circ}$ because of the mechanical limitation of the measurement system. As shown, the 3-D patterns are almost circularly symmetric around $z$-axis.

The antenna radiation pattern for $\theta$ and $\varphi$-polarized components in the three principal cut planes ( $x z$-, $y z$ - and $x y$-plane) are illustrated in Fig. 7. As shown, the $\varphi$-polarized field pattern for both frequencies is small compared to the $\theta$-polarized pattern. This results to the dominant vertical polarization of the antenna. The radiated power pattern of the antenna in the $2.45 \mathrm{GHz}$ in the $x z$ and $y z$-plane shows the peak of the beam directed toward $\theta= \pm 120^{\circ}$. The pattern for $\theta=0^{\circ}$ has a null

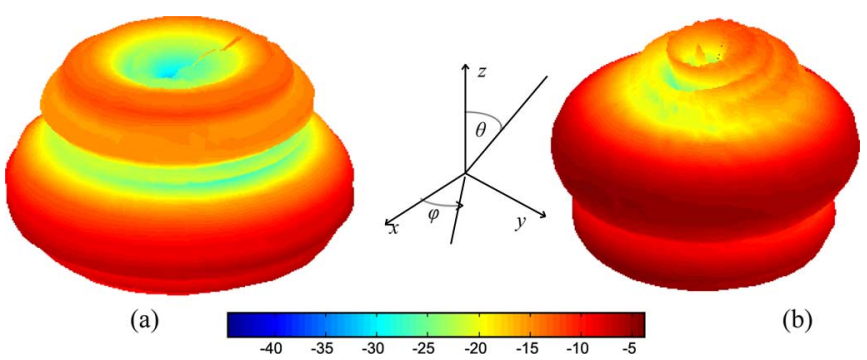

Fig. 6. Measured 3-D power pattern (decibels) of the meander line antenna with the coupled rectangular patch (a) $2.45 \mathrm{GHz}$ and (b) $5.25 \mathrm{GHz}$.

value less than $-30 \mathrm{dBi}$. The power pattern in the $x y$-plane has a nearly uniform variation with an average value of $-3 \mathrm{dBi}$ and peak power gain of $-2.7 \mathrm{dBi}$ for $\varphi=0^{\circ}$. In the $5.25 \mathrm{GHz}$, for yz-plane the peak gain of $2.5 \mathrm{dBi}$ is given for $\theta= \pm 90^{\circ}$. In the $x y$-plane the antenna pattern is somewhat directed toward $\varphi=180^{\circ}$ and gives the peak power gain of $3.7 \mathrm{dBi}$ [see Fig. 7(f)]; the directed pattern confirms the radiation of the rectangular patch in the $5 \mathrm{GHz}$ band. The average power gain in the $x y$-plane is almost $2.6 \mathrm{dBi}$. The measured peak power gain of the antenna in the 2.45 and $5.25 \mathrm{GHz}$ are tabulated in Table II.

The communication in wireless environments is conducted by the multipath propagation of the waves. The angular spread of the incident field on the antenna depending on the propagation environment can be large. For instance, isotropically field scatters can be considered for indoor channel. Therefore, the given small antenna gain $(-3 \mathrm{dBi})$ in the azimuth plane in the $2.4 \mathrm{GHz}$ is not a critical value for communication. Furthermore, the rotation of the antenna in relation to the propagation channel is not essentially vertical.

\section{ANTENNA EFFICIENCY MEASUREMENT}

Mean effective gain (MEG) gives the performance of an antenna system in multipath environments. It is defined as the ratio of the average power received by an antenna in a random scattering environment to the total average power incident on to the antenna [4]-[6]. MEG depends on the antenna pattern and the multipath propagation channel. For a special environment with isotropically field scatters and un-polarized case, cross-polarization ratio of unity, MEG is directly related to the antenna efficiency $(\eta)$, i.e., $\mathrm{MEG}=\eta / 2$.

Reverberation chamber is an example of the special multipath channel [7]. The received mean power by an arbitrary antenna in the reverberation chamber is independent of the antenna rotation in relation to the field scattering environment. Also, the multipath propagation can be reproduced [8]. Therefore, the efficiency of an arbitrary antenna can be measured by comparison between the average detected power with an efficient antenna (for instance a matched dipole) and the average power of the test antenna at the same multipath environment.

We have used Supelec classical reverberation chamber for the measurement of the antenna efficiency [8], [10]. The dimensions of the chamber are $3 \times 1.8 \times 2.8 \mathrm{~m}^{3}$. The measured average powers received by the meander antenna in the 2.45 and $5.25 \mathrm{GHz}$ are -31.7 and $-41.7 \mathrm{dBm}$, respectively. The measured average powers received through standard half-wave dipoles are -28.9 and $-40.9 \mathrm{dBm}$, respectively. This results to 2.8 and $0.8 \mathrm{~dB}$ reduced signal power in the meander antenna port compared to the standard dipoles. Considering the matched dipoles as the reference (i.e., $100 \%$ efficient) the total efficiency of the meander antenna would be $52 \%$ and $83 \%$ in the operating bands, respectively. MEG of a well matched dipole is $-0.5 \mathrm{~dB}$, therefore MEG of the meander antenna is -3.3 and $-1.3 \mathrm{~dB}$ for the firstand the second-resonances. Note that the given results include the attenuation of the ferrite beads attached to the coaxial feed cable. 
TABLE II

Measured Peak Power Gain in Three Principal Cut Planes IN the 2.45 and 5.25 GHz

\begin{tabular}{|c|c|c|c|}
\hline Frequency $(\mathbf{G H z})$ & $\begin{array}{c}\text { Peak power gain } \\
\text { (dBi),yz-plane }\end{array}$ & $\begin{array}{c}\text { Peak power gain } \\
\text { (dBi),xy-plane }\end{array}$ & $\begin{array}{c}\text { Peak power gain } \\
\text { (dBi),xz-plane }\end{array}$ \\
\hline $\mathbf{2 . 4 5}$ & 5 at $\theta= \pm 120^{\circ}$ & -2.7 at $\varphi=0^{\circ}$ & 5.3 at $\theta= \pm 120^{\circ}$ \\
\hline $\mathbf{5 . 2 5}$ & 2.5 at $\theta= \pm 90^{\circ}$ & 3.7 at $\varphi=180^{\circ}$ & 3.7 at $\theta=-90^{\circ}$ \\
\hline
\end{tabular}

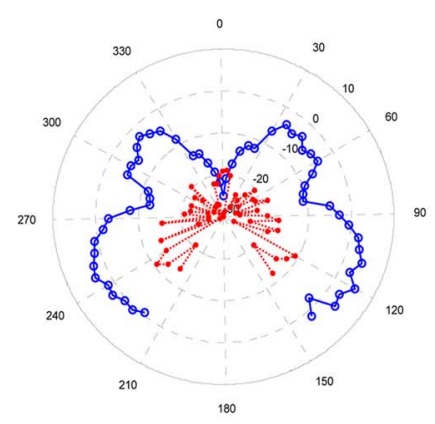

(a)

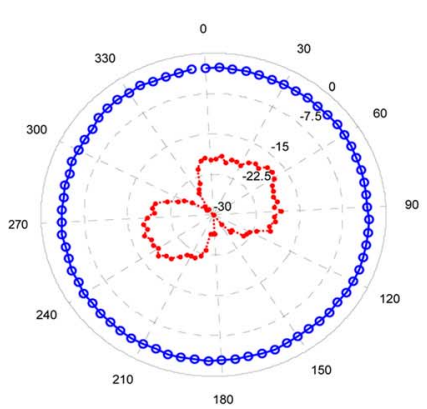

(c)

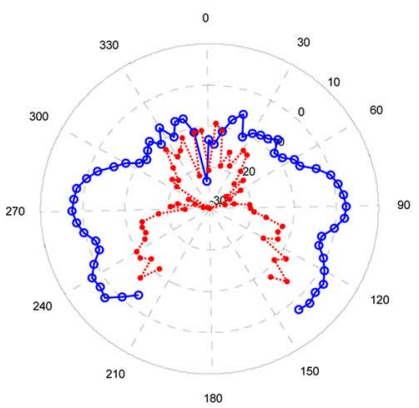

(e)

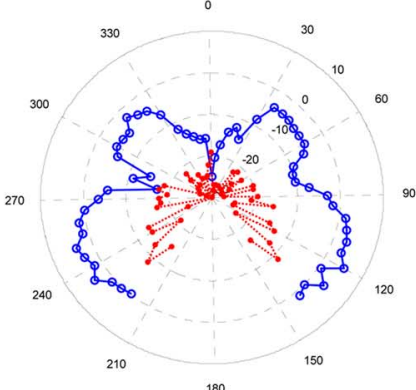

(b)

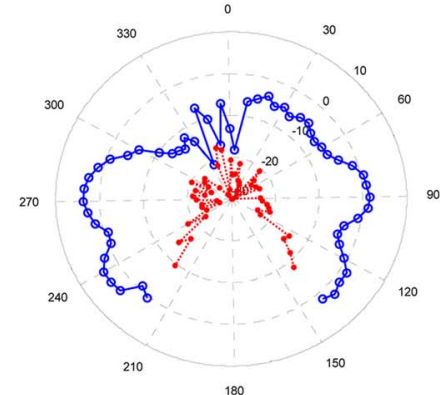

(d)

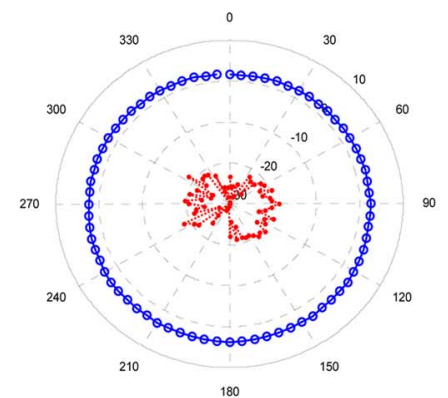

(f)
Fig. 7. Measured $\theta$-polarized $-\circ-$ and $\varphi$-polarized $-\bullet$ antenna gain patterns (dBi) at (a) $2.45 \mathrm{GHz} x z$-plane, (b) $2.45 \mathrm{GHz} y z$-plane, (c) $2.45 \mathrm{GHz} x y$-plane, (d) $5.25 \mathrm{GHz} x z$-plane, (e) $5.25 \mathrm{GHz} y z$-plane, (f) $5.25 \mathrm{GHz} x y$-plane.

\section{Rectangular Patch Length EFFects on THE RESONANCE FREQUENCIES}

In Section II, it has been shown that the second-resonance is realized using the coupled rectangular patch. Based on the illustrated current distribution we have concluded to use the length $\left(L_{P}\right)$ of the rectangular patch for tuning of the second-resonance frequency to the commercial WLANs, 5.25, 5.59, or $5.77 \mathrm{GHz}$. It is essential to keep a small gap distance $\left(t_{g}=0.2 \mathrm{~mm}\right)$ between the rectangular patch and the shaped ground plane. By this assumption, the return-loss for various lengths $\left(L_{p}\right)$ is measured. Fig. 8 illustrates the return-loss versus frequency for three optimized patch lengths $\left(L_{p}=20,16,15 \mathrm{~mm}\right)$ that cover all the frequency bands of commercial WLANs. As shown, by the variation of the $L_{p}$, the first-resonance frequency is almost constant in the $2.4 \mathrm{GHz}$ band and the second-resonance can be tuned to each one of the WLAN frequencies. The impedance bandwidth of the antenna

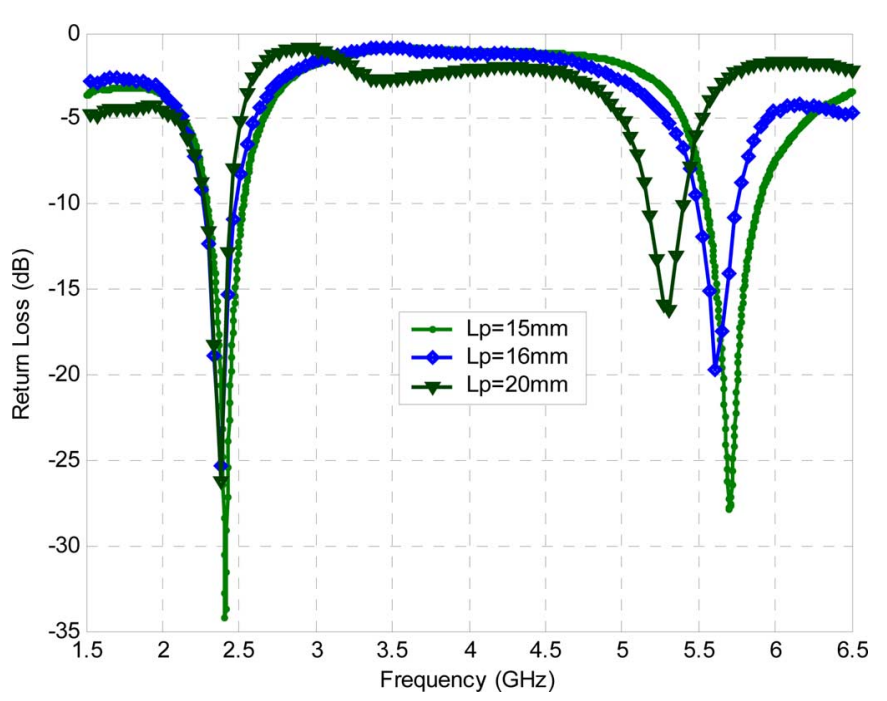

Fig. 8. Measured return-loss versus frequency for three optimized $L p(=20,16,15 \mathrm{~mm})$ values for IEEE $802.11 \mathrm{a}$, b WLAN frequency band coverage.

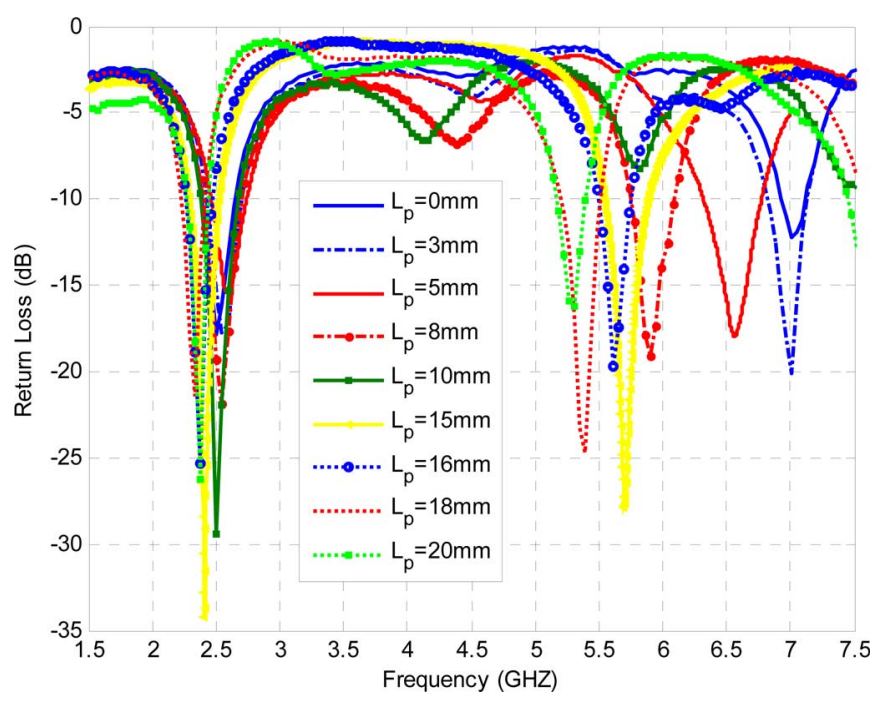

Fig. 9. Measured return-loss (decibels) versus frequency (gigahertz) for $L_{p}$ (millimeters) variation in the range of 0 and $20 \mathrm{~mm}$.

for all optimized $L_{p}$ and for the return-loss less than $-10 \mathrm{~dB}$ is better than 270 and $315 \mathrm{MHz}$ in the 2.4 and $5 \mathrm{GHz}$ bands, respectively.

Fig. 9 shows the measured return-loss for wide range variation of $L_{p}$. As shown, modifying the length, $L_{p}$, from $20 \mathrm{~mm}$ to zero with the constant air gap, moves the second-resonance frequency from 5.25 to $7 \mathrm{GHz}$ (28\% variation) and the first-resonance frequency varies almost $10 \%$ at the range of 2.33 to $2.5 \mathrm{GHz}$. The bandwidth in the $2.4 \mathrm{GHz}$ band is $11 \%$ and for the second-resonance is almost $6 \%$. The measured return-loss at the first-resonance is better than $-15 \mathrm{~dB}$ and for the second-resonance is less than $-13 \mathrm{~dB}$ with the exception for $L p=$ $10 \mathrm{~mm}$ where there is not a good impedance matching. Fig. 10 shows 


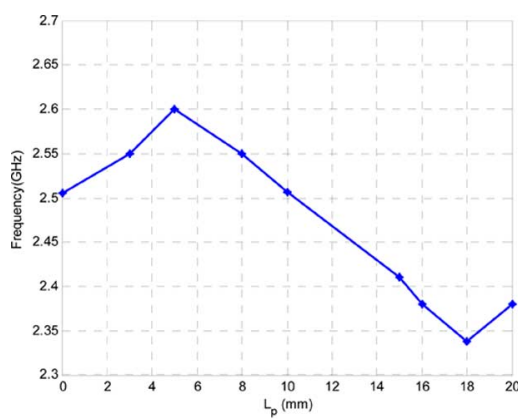

(a)

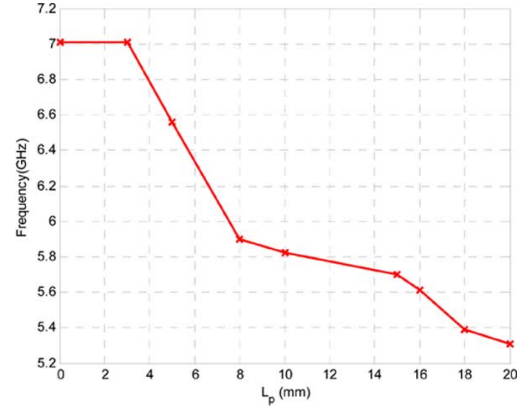

(b)

Fig. 10. Resonance frequency variation (gigahertz) versus patch length $L p$ (millimeters) for (a) $2.4 \mathrm{GHz}$ and (b) $5 \mathrm{GHz}$ frequency band.

the resonance frequency variations as a function of the patch length $\left(L_{p}\right)$. The second-resonance frequency $\left(\mathrm{f}_{2}\right)$ nonlinearly varies from 7 to $5.25 \mathrm{GHz}$ with the length $L_{p}$; meanwhile, the first-resonance $\left(\mathrm{f}_{1}\right)$ is almost constant with small variations around $2.45 \mathrm{GHz}$. This feature of the antenna makes the design flexible for use in wide frequency range applications without need to large modifications of the antenna structure.

We note that the width of the rectangular patch $\left(W_{p}\right)$ somewhat changes the second-resonance location. For instance, for $W=W_{p} / 2$ and $L_{p}=20 \mathrm{~mm}$ the second-resonance is moved from 5.25 to $5.59 \mathrm{GHz}$. The length and the width of the rectangular patch can be combined together for fine tuning of the location of the second-resonance.

\section{CONCLUSION}

A low profile dual-band/wideband meander line antenna is designed and analyzed to support the IEEE $802.11 \mathrm{a}$, b wireless LANs (2.42-2.48 GHz and 5.15-5.35 GHz). The first-resonance is supported by the meander antenna and the second-resonance is generated by a back coupled rectangular patch. Wide-band operation of $11 \%$ and $6 \%$ is given for the 2.4 and $5 \mathrm{GHz}$ bands. It is shown that by adjusting the length of the rectangular patch, the second-resonance can be widely adjusted within 5.25-7 GHz frequency range and the first-resonance frequency remains almost constant in the $2.4 \mathrm{GHz}$ band. The performance characteristics of the antenna include, return-loss, 3-D pattern, gain and efficiency are measured. The given characteristics of the antenna together with small size $(31 \times 8 \times 1.6 \mathrm{~mm})$ and low price make it appropriate for use on notebook, PC, PDA and other WLAN communications devices.

\section{ACKNOWLEDGMENT}

The author would like to thank Prof. J. C. Bolomey and Prof. A. Azoulay for the good comments related to this paper. Thanks are also owed to Dr. N. Ribiere-Tharaud for the measurement of the antenna pattern.

\section{REFERENCES}

[1] L. C. Godara, Handbook of Antennas in Wireless Communication. Boca Raton, FL: CRC Press, 2002.

[2] M. Ali, S. S. Stuchly, and K. Caputa, "A wide-band dual meandersleeve antenna," J. Electromagn. Waves and Applicat., vol. 10, no. 9, pp. 1223-1236, 1996.

[3] C.-W. P. Huang, A. Z. Elsherbeni, J. J. Chen, and C. E. Smith, "FDTD characterization of meander line antennas for RF and wireless communications," Progress in Electromagn. Res., PIER 24, pp. 185-199, 1999.

[4] M. G. Douglas, M. Okoniewski, and M. A. Stuchly, "A planar diversity antenna for handheld PCS devices," IEEE Trans. Veh. Tech., vol. 47, no. 3, pp. 747-754, 1998.

[5] T. Taga, "Analysis for mean effective gain of mobile antennas in land mobile radio environments," IEEE Trans. Veh. Tech., vol. 39, pp. 117-131, May 1990.

[6] K. Kalliola et al., "Angular power distribution and mean effective gain of mobile antenna in different propagation environments," IEEE Trans. Veh. Tech., vol. 51, no. 5, pp. 823-838, 2002.

[7] K. Rosengren and P.-S. Kildal, "Study of distribution of modes and plane waves in reverberation chamber for characterization of antennas in multipath environment," Microw. Opt. Tech. Lett., vol. 30, no. 20 , pp. 386-391, Sept. 2001

[8] A. Khaleghi, J. C. Bolomey, and A. Azoulay, "On the statistics of reverberation chambers and applications for wireless antenna test," in Proc. IEEE Int. Symp. on Antennas and Propagation (AP-S), Albuquerque, NM, Jul. 2006, pp. 3561-3564.

[9] P. J. Massey and K. R. Boyle, "Controlling the effects of feed cable in small antenna measurements," in IEE, ICAP 2003, April 2003.

[10] A. Khaleghi, "Diversity techniques with parallel dipole antennas: radiation pattern analysis," Progress In Electromagn. Res., PIER 64, pp. 23-42, 2006.

[11] M. Ali, G. J. Hayes, H. Huan-Sheng, and R. A. Sadler, "Design of a multiband internal antenna for third generation mobile phone handsets," IEEE Trans. Antennas Propag., vol. 51, no. 7, pp. 1452-1461, Jul. 2003. 